\title{
New setting of neurally adjusted ventilatory assist for noninvasive ventilation by facial mask: a physiologic study
}

Federico Longhini ${ }^{1 \dagger}$, Chun Pan ${ }^{2 \dagger}$, Jianfeng Xie ${ }^{2}$, Gianmaria Cammarota ${ }^{3}$, Andrea Bruni ${ }^{4}$, Eugenio Garofalo ${ }^{4}$, Yi Yang ${ }^{2}$, Paolo Navalesi ${ }^{4}$ and Haibo Qiu ${ }^{2^{*}}$

\begin{abstract}
Background: Noninvasive ventilation (NIV) is generally delivered using pneumatically-triggered and cycled-off pressure support (PSP) through a mask. Neurally adjusted ventilatory assist (NAVA) is the only ventilatory mode that uses a nonpneumatic signal, i.e., diaphragm electrical activity (EAdi), to trigger and drive ventilator assistance. A specific setting to generate neurally controlled pressure support $\left(\mathrm{PS}_{N}\right)$ was recently proposed for delivering NIV by helmet. We compared $P_{N}$ with PSP and NAVA during NIV using a facial mask, with respect to patient comfort, gas exchange, and patientventilator interaction and synchrony.
\end{abstract}

Methods: Three 30-minute trials of NIV were randomly delivered to 14 patients immediately after extubation to prevent post-extubation respiratory failure: (1) $P S_{P}$, with an inspiratory support $\geq 8 \mathrm{cmH}_{2} \mathrm{O}$; (2) NAVA, adjusting the NAVA level to achieve a comparable peak EAdi (EAdi peak) as during PSP; and (3) PS $S_{N}$, setting the NAVA level at 15 $\mathrm{CmH}_{2} \mathrm{O} / \mu \mathrm{V}$ with an upper airway pressure (Paw) limit to obtain the same overall Paw applied during PSp. We assessed patient comfort, peak inspiratory flow (PIF), time to reach PIF $\left(\mathrm{PIF}_{\text {time }}\right)$, EAdi peak, arterial blood gases, pressure-time

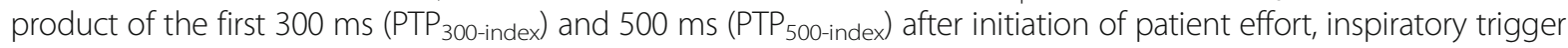
delay (Delay ${ }_{\text {TR-insp }}$ ), and rate of asynchrony, determined as asynchrony index (Al\%). The categorical variables were compared using the McNemar test, and continuous variables by the Friedman test followed by the Wilcoxon test with Bonferroni correction for multiple comparisons $(p<0.017)$.

Results: $P S_{N}$ significantly improved patient comfort, compared to both $\operatorname{PS}_{P}(p=0.001)$ and NAVA $(p=0.002)$, without differences between the two latter $(p=0.08)$. PIF $(p=0.109)$, EAdi peak $(p=0.931)$ and gas exchange were similar between modes. Compared to $\mathrm{PS}_{\mathrm{P}}$ and NAVA, $\mathrm{PS}_{\mathrm{N}}$ reduced $\mathrm{PIF}_{\text {time }}(p<0.001)$, and increased $\mathrm{PTP}_{300 \text {-index }}(p=0.004)$ and $\operatorname{PTP}_{500 \text {-index }}(p=0.001)$. NAVA and PS $S_{N}$ significantly reduced DelayTR-insp, as opposed to $\mathrm{PS}_{P}(p<0.001)$. During both NAVA and $P S_{N}, A l \%$ was $<10 \%$ in all patients, while Al\% was $\geq 10 \%$ in 7 patients (50\%) with $P S_{P}(p=0.023$ compared with both NAVA and $P S_{N}$ ).

Conclusions: Compared to both $\mathrm{PS}_{\mathrm{P}}$ and NAVA, $\mathrm{PS}_{\mathrm{N}}$ improved comfort and patient-ventilator interaction during NIV by facial mask. $P S_{N}$ also improved synchrony, as opposed to $\mathrm{PS}_{\mathrm{P}}$ only.

Trial registration: ClinicalTrials.gov, NCT03041402. Registered (retrospectively) on 2 February 2017.

Keywords: Noninvasive ventilation, Pressure support ventilation, Neurally adjusted ventilatory assist, Patient-ventilator interaction, Ventilator performance, Patient-ventilator asynchrony

\footnotetext{
* Correspondence: haiboq2000@gmail.com; haiboq2000@163.com

${ }^{\dagger}$ Equal contributors

2Department of Critical Care Medicine, Nanjing Zhong-Da Hospital, Southeast

University School of Medicine, 87 Dingjiagiao Road, Nanjing 210009, China

Full list of author information is available at the end of the article
} 


\section{Background}

Noninvasive ventilation (NIV) is increasingly used for treating acute respiratory failure (ARF) $[1,2]$ and is commonly applied using a facial mask [3] and pneumatically triggered and cycled-off pressure support $\left(\mathrm{PS}_{\mathrm{P}}\right)$ [4]. Although better tolerated than invasive mechanical ventilation, NIV is characterized by drawbacks such as poor patient-ventilator interaction and discomfort [5], which are major determinants of NIV failure.

In particular, the pneumatic signals, i.e., flow, volume and airway pressure (Paw), are leak-sensitive [6] and frequently cause patient-ventilator asynchrony [7]. The only mode not utilizing pneumatic signals to trigger and drive the ventilator is neurally adjusted ventilator assist (NAVA). In fact, with NAVA the ventilator assistance is under the control of the diaphragm electrical activity (EAdi) [8]. In contrast to $\mathrm{PS}_{\mathrm{P}}$ NAVA has been repeatedly shown to improve patient-ventilator interaction and reduce asynchronies, both during invasive ventilation $[9,10]$ and NIV $[4,11-15]$. However, NAVA is characterized by a lower rate of pressurization than $\mathrm{PS}_{\mathrm{P}}$ [4].

Recently, a specific NAVA setting has been proposed to generate EAdi-controlled pressure support $\left(\mathrm{PS}_{\mathrm{N}}\right)$ in patients receiving either invasive ventilation [16] or NIV by helmet [4]. PS $_{\mathrm{N}}$ consists of increasing the usercontrolled gain factor (NAVA level) at the maximum level, while limiting peak airway pressure $\left(\mathrm{Paw}_{\text {peak }}\right)$ by adjusting the upper pressure limit $[4,16]$.

During NIV delivered by helmet, compared to both $\mathrm{PS}_{\mathrm{P}}$ and NAVA, $\mathrm{PS}_{\mathrm{N}}$ results in better pressurization and triggering performance, which improves patient comfort while reducing EAdi, without affecting the respiratory rate and gas exchange [4]. Due to the different characteristics of helmets and masks, it is unclear whether these advantages could be extended to NIV delivered by mask. This physiological study aims at comparing $\mathrm{PS}_{\mathrm{N}}$ with $\mathrm{PS}_{\mathrm{P}}$ and NAVA, with respect to the patient's comfort (primary endpoint), breathing pattern, respiratory drive, gas exchange, pressurization and triggering performance and patientventilator synchrony (additional endpoints).

\section{Methods}

The present physiologic, crossover, randomized study was conducted from March to September 2013 in the Intensive Care Units (ICUs) of the University Hospital "Maggiore della Carità" (Novara, Italy) and the ZhongDa Hospital, Southeast University (Nanjing, China). The study was approved by the local Ethics Committees "A.O.U Maggiore della Carità" in Novara, Italy (protocol $n^{\circ}$ 64/12) and the Research Ethics Board of Zhongda Hospital, Southeast University, Nanjing, China (2013ZDSYLL097.0). Written informed consent was obtained from the patients for publication of their individual details and accompanying images in this manuscript. The consent forms are held by the authors and are available for review by the Editor-in-Chief. At the time the study was conducted, trial registration was not mandatory for this type of investigation; however, the trial was retrospectively registered at ClinicalTrials.gov (NCT03041402). We followed the Consolidated Standards of Reporting Trials (CONSORT) recommendations for reporting of randomized trials [17].

\section{Patients}

We considered any patient eligible who was $\geq 18$ years of age and admitted to the ICU, and who was orally intubated and undergoing invasive mechanical ventilation for at least 48 hours. The inclusion criteria were: (1) consciousness, as indicated by a Glasgow Coma Scale (GCS) of 11 (i.e. spontaneous eye opening, response to command and no verbal response because of the endotracheal tube in place); (2) no infusion of midazolam or propofol in the previous 24 hours or 4 hours, respectively; and (3) readiness for extubation with indication, prior to extubation, to receive NIV to prevent postextubation respiratory failure. The patients were considered to be eligible for the spontaneous breathing trial if they met the following criteria [18]: (1) GCS $\geq 8$; (2) presence of clearly audible cough during suctioning; (3) tracheal suctioning $\leq 2 /$ hour; (4) normal sodium blood values; (5) core temperature $<38.5{ }^{\circ} \mathrm{C}$ during the previous 8 hours; (6) arterial oxygen tension $\left(\mathrm{PaO}_{2}\right)$ to fraction of inspired oxygen $\left(\mathrm{FiO}_{2}\right)$ ratio $\left(\mathrm{PaO}_{2} / \mathrm{FIO}_{2}\right) \geq 200$ with positive end-expiratory pressure (PEEP) $\leq 5 \mathrm{cmH}_{2} \mathrm{O}$; (7) $\mathrm{FiO}_{2} \leq$ 0.4 ; (8) heart rate $\leq 125$ beats $/ \mathrm{min}$; and (9) systolic blood pressure $>90 \mathrm{mmHg}$ without epinephrine or norepinephrine infusion and with dopamine infusion $\leq 5 \mathrm{mcg} / \mathrm{kg} / \mathrm{min}$. The patients considered to be at risk of extubation failure exhibited at least one of the following: (1) more than one consecutive failure of the weaning trial [19]; (2) arterial partial pressure of carbon dioxide $\left(\mathrm{PaCO}_{2}\right)>45 \mathrm{mmHg}$ at the end of the 30-min spontaneous breathing trial [20]; (3) chronic respiratory disorders [19]; and (4) chronic heart failure [19].

The exclusion criteria were as follows: (1) need for analgaesic or sedative drugs; (2) recent cervical spine injury; (3) obstructive sleep apnoea syndrome; (4) pregnancy; (5) contraindications to placement of a nasal-gastric feeding tube; (6) inclusion in other research protocols; and (7) lack of consent.

\section{Study protocol}

After the patient's enrolment in the study, the nasalgastric feeding tube in place was replaced by the EAdi catheter (Maquet Critical Care, Solna, Sweden) [9]. The correct positioning was ascertained as previously described [9]. The study was performed using a standard Servo-I ventilator (Maquet Critical Care, Solna, Sweden) equipped with NAVA module and NIV software for air 
leaks. The facial mask was individually selected for each patient based on their anthropometric characteristics to minimize air leaks and optimize patient tolerance; the facial mask was selected from among three different models: FreeMotion RT041 Non Vented Full Face Mask (Fisher and Paykel, Auckland, New Zealand); Ultra Mirage FFM-NV (ResMed, San Diego, CA, USA); and PerforMax Face Mask (Philips Respironics, Murrysville, PA, USA).

Immediately after extubation, we performed a 15-min $\mathrm{PS}_{\mathrm{P}}$ trial, setting the inspiratory pressure support $\geq 8$ $\mathrm{cmH}_{2} \mathrm{O}$ to obtain a tidal volume of $6-8 \mathrm{~mL} \cdot \mathrm{kg}^{-1}$ of ideal body weight, with the fastest rate of pressurization and $\mathrm{I} / \mathrm{E}$ cycling at $35 \%$ of peak inspiratory flow (PIF). All patients subsequently underwent three 30 -min trials in random order: (1) $\mathrm{PS}_{\mathrm{P}}$, with the settings obtained in the aforementioned trial; (2) NAVA, adjusting the NAVA level in order to achieve a comparable peak EAdi (EAdi peak $_{\text {pas }}$ ) as during the $\mathrm{PS}_{\mathrm{P}}$ trial, with a safety Paw upper limit of 30 $\mathrm{cmH}_{2} \mathrm{O}[4,15]$; and (3) $\mathrm{PS}_{\mathrm{N}}$, setting the NAVA level at its maximum (i.e., $15 \mathrm{cmH}_{2} \mathrm{O} / \mu \mathrm{V}$ ), and an upper Paw limit to obtain the same overall Paw applied during the $\mathrm{PS}_{\mathrm{P}}$ trial $[4,16,21]$. During both NAVA and $\mathrm{PS}_{\mathrm{N}}$, the trigger sensitivity was set at $0.5 \mu \mathrm{V}$ while the default cycling-off was $70 \%$ EAdi $_{\text {peak }}$, as fixed by the manufacturer [21]. PEEP was set by the attending physicians in a range between 5 $\mathrm{cmH}_{2} \mathrm{O}$ and $10 \mathrm{cmH}_{2} \mathrm{O}$, and it remained unmodified throughout the entire study period. The $\mathrm{FiO}_{2}$ was regulated to obtain peripheral oxygen saturation $\left(\mathrm{SpO}_{2}\right)$ between $94 \%$ and $96 \%$, before starting the protocol, and it remained unmodified throughout the study period.

The three modes of ventilation were applied according to a computer-generated random sequence using sealed, opaque, numbered envelopes. The envelopes were kept in the head nurse's office in both institutions. The envelope was opened by the nurse in charge of the patient, and the prescribed sequence of modes was communicated to the investigators.

The predefined criteria for protocol interruption were as follows: (1) need for emergency re-intubation; (2) $\mathrm{SpO}_{2}<90 \%$; (3) acute respiratory acidosis, as defined by $\mathrm{PaCO}_{2}>50 \mathrm{mmHg}$ and $\mathrm{pH}<7.30$; (3) inability to expectorate secretions; (4) hemodynamic instability (i.e., need for continuous infusion of dopamine or dobutamine $>5 \mu \mathrm{g} \cdot \mathrm{kg}^{-1} \cdot \mathrm{min}^{-1}$, norepinephrine $>0.1 \mu \mathrm{g} \cdot \mathrm{kg}^{-1} \cdot \mathrm{min}^{-1}$ or epinephrine or vasopressin at any dosage to maintain mean arterial blood pressure $>60 \mathrm{mmHg}$ ); (5) life-threatening arrhythmias or electrocardiographic signs of ischaemia; or (6) loss of 2 or more points on the GCS.

\section{Data acquisition and analysis}

Airflow, Paw and EAdi were acquired from the ventilator using an RS232 interface at a sampling rate of $100 \mathrm{~Hz}$ and were recorded on a computer using dedicated software (ServoTracker V. 4.0, Maquet Critical Care, Solna,
Sweden). The last minute of each trial was manually analysed off-line using customized software based on Microsoft Excel, as previously described [9].

Comfort was assessed through an 11-point numeric rating scale (NRS), as previously reported [4, 22-24]. Before protocol initiation, all patients received a detailed explanation of the NRS. The patients were asked to evaluate their comfort level, indicating a number between 0 (worst possible comfort) and 10 (best possible comfort) using an ICU-adapted large-printed scale including numbers and descriptors [23]. The scores obtained were recorded without additional indications or comments [24].

Breathing pattern was assessed by determining (1) mechanical inspiratory time $\left(\mathrm{TI}_{\mathrm{mec}}\right)$, breath duration $\left(\mathrm{TTOT}_{\text {mec }}\right)$ and rate of ventilator cycling $\left(\mathrm{RR}_{\text {mec }}\right)$ from the flow tracing, and (2) the patient's own (neural) inspiratory time $\left(\mathrm{TI}_{\text {neu }}\right)$, breath duration $\left(\mathrm{TTOT}_{\text {neu }}\right)$ and respiratory rate $\left(\mathrm{RR}_{\text {neu }}\right)$ from the EAdi tracing. The mechanical (TI/TTOT $\left.\mathrm{Tec}_{\text {mec }}\right)$ and neural $\left(\mathrm{TI} / \mathrm{TTOT}_{\text {neu }}\right)$ inspiratory duty cycles were also calculated $[15,25]$. Air leaks were computed over one minute as the difference between inspiratory and expiratory tidal volumes times $R R_{\text {mec }}$ and were expressed as percentage of the exhaled volume over one minute [15, 25]. Moreover, we measured Paw $_{\text {peak }}$, peak inspiratory flow (PIF) and the time to reach PIF from the onset of the patient's effort $\left(\mathrm{PIF}_{\text {time }}\right)$. EAdi ${ }_{\text {peak }}$ was also determined as an index of respiratory drive [26]. Gas exchange was assessed at the end of each trial by sampling arterial blood from a catheter already inserted for clinical purposes.

To evaluate the pressurization performance, we computed the pressure-time product (PTP) of the first $200 \mathrm{~ms}$ from the onset of the ventilator pressurization $\left(\mathrm{PTP}_{200}\right)$, and the PTP of the first $300 \mathrm{~ms}$ and $500 \mathrm{~ms}$ from the onset of the neural effort, expressed as the percentage of the area of ideal pressurization $\left(\mathrm{PTP}_{300}\right.$-index and PTP $_{500-\text { index }}$, respectively) $[4,24,27,28]$. The ideal PTP was computed considering a perfectly squared rectangle on the Paw-time tracing, with the height of the actual Paw above PEEP and the width of the time window considered (i.e., 0.3 second and 0.5 second from the onset of the inspiratory effort, assessed from the EAdi tracing, for $\mathrm{PTP}_{300 \text {-index }}$ and $\mathrm{PTP}_{500 \text {-index }}$, respectively) $[4,24,27,28]$. The triggering performance was evaluated by determining the pressure drop $\left(\Delta \mathrm{P}_{\text {trigger }}\right)$ and PTP of Paw $\left(\mathrm{PTP}_{\mathrm{t}}\right)$ during the triggering phase $[4,24,27,28]$.

To assess patient-ventilator synchrony, we computed the inspiratory trigger delay $\left(\right.$ Delay $_{\mathrm{TR} \text {-insp }}$ ), as the time lag between the onsets of neural inspiration and ventilator support, and the expiratory trigger delay (Delay ${ }_{T R}$ exp), as the time lag between the fall towards baseline of EAdi and the end of ventilator support. The time during which respiratory effort and ventilator assistance were synchronous, indexed to the $\mathrm{TI}_{\text {neu }}\left(\mathrm{Time}_{\text {synch }} / \mathrm{TI}_{\text {neu }}\right)$, was 
also computed $[4,24,27]$. The asynchrony index (AI\%) was calculated as the total number of asynchronies (i.e., ineffective efforts, auto-triggers and double-triggers) divided by the sum of triggered and non-triggered breaths [7]. An AI\% $\geq 10 \%$ was considered to indicate a clinically relevant rate of asynchronies [7].

\section{Statistical analysis}

To detect an increase in comfort of 2.5 [4], with $\alpha$ risk of 0.05 and $\beta$ risk of 0.20 , a sample of 12 patients was deemed necessary. Because this calculation was based on a pairwise comparison and we actually compared three conditions, we applied the Bonferroni correction, which reduced the $\alpha$ risk from 0.05 to 0.017 , increasing the sample size up to 14 patients. We used non-parametric tests because of the relatively small number of patients. The data are reported as median values $(25-75 \%$ interquartile), unless otherwise specified. All continuous variables were compared between modes using the Friedman test and then by the Wilcoxon test; the Bonferroni correction was applied for multiple comparisons $(p<0.017)$. We compared the categorical data using the McNemar test. The Spearman rank correlation test was used to ascertain the correlation between each individual comfort score and the corresponding $\mathrm{PTP}_{300 \text {-index }}, \mathrm{PTP}_{500 \text {-index }}$, $\mathrm{PTP}_{\mathrm{t}}$, Delay $\mathrm{TR}_{\mathrm{T} \text {-insp }}$, PIF and $\mathrm{PIF}_{\text {time }}$. For these comparisons, we considered two-sided $p$ values $<0.05$ significant. All statistical analyses were performed using the Sigmaplot v. 12.0 (Systat Software Inc., San Jose, CA, USA). No interim analysis has been planned or conducted.

\section{Results}

We enrolled 14 consecutive patients. The patients' study flow is shown in Fig. 1. All patients completed the study protocol without any complication and were included in the data analysis. No patient required either sedative or analgaesic drugs during the study period. No patients met any criteria for post-extubation respiratory failure requiring re-intubation. The patients' demographic and anthropometric characteristics are shown in Table 1.

\section{Comfort}

The individual values of the comfort score for all the patients and their median and interquartile range are depicted in Fig. $2 . \mathrm{PS}_{\mathrm{N}}$ significantly improved patient comfort $(7(7 ; 8))$, compared to both $\mathrm{PS}_{\mathrm{P}}(5(5 ; 6) ; p=0.001)$ and NAVA $(5(5 ; 7)) ; p=0.002)$, with no differences between $\mathrm{PS}_{\mathrm{P}}$ and NAVA $(p=0.08)$. Comfort was directly correlated to $\mathrm{PTP}_{300 \text {-index }}(\rho=0.51, p<0.001)$ and to $\operatorname{PTP}_{500-\text { index }}(\rho=0.46, p=0.002)$; comfort was also inversely correlated to Delay TR-insp $(\rho=-0.58, p<0.001)$, PIF $_{\text {time }}$ ( $\rho$ $=-0.47, p=0.002)$ and PTPt $(\rho=-0.55, p<0.001)$ while not correlated to PIF ( $\rho=-0.14, p=0.369)$.

\section{Breathing pattern, respiratory drive and gas exchange}

As reported in Table 2, the breathing pattern was not different between modes. Only TI/TTOT ${ }_{\text {mec }}$ was significantly lower during $\mathrm{PS}_{\mathrm{B}}$ as opposed to both NAVA ( $p=$ $0.007)$ and $\mathrm{PS}_{\mathrm{N}}(p=0.010)$. $\mathrm{Paw}_{\text {peak }}(p=0.607)$, air leaks $(p=0.395)$ and respiratory drive, as indicated by the $\operatorname{EAdi}_{\text {peak }}(p=0.931)$, were also not different between modes. PIF did not differ between the three modes of ventilation $(p=0.109)$, while PIF time was significantly

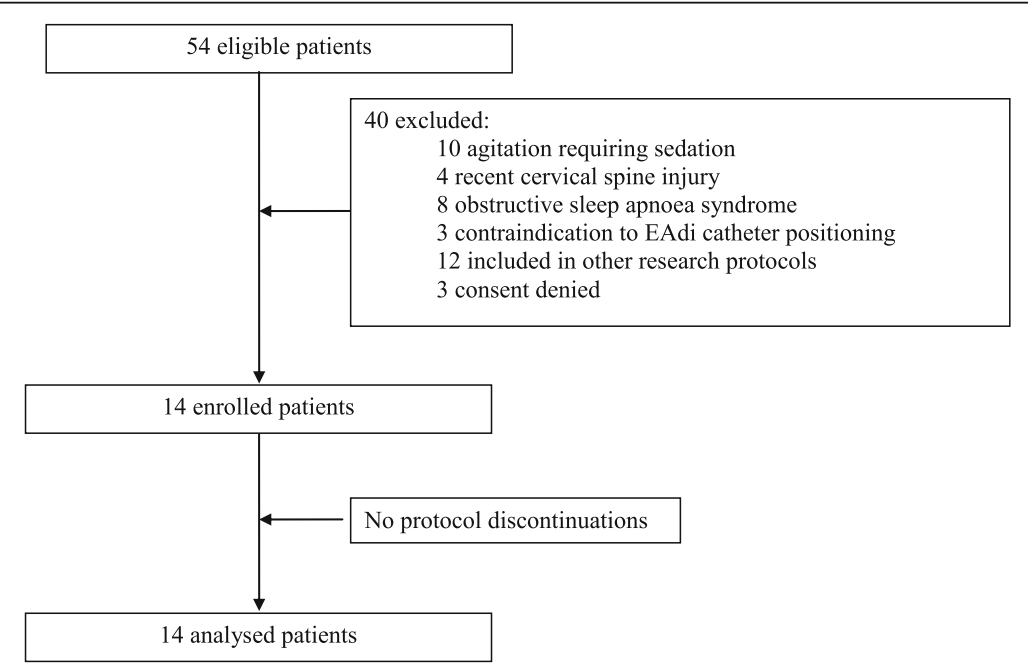

Fig. 1 Enrolment of the study participants. The flow of patient assessment and inclusion in the protocol is shown. A total of 54 patients were considered eligible for the study, having met all inclusion criteria: 40 patients were excluded from the study because they met one or more of the exclusion criteria. Therefore, 14 patients were included in the study. No protocol discontinuations were recorded. EAdi diaphragm electrical activity 
Table 1 Patient characteristics at enrolment

\begin{tabular}{llllllll}
\hline Patient & $\begin{array}{l}\text { Weight: } \\
\mathrm{kg}\end{array}$ & $\begin{array}{l}\mathrm{BMl} \\
\mathrm{kg} / \mathrm{m}^{2}\end{array}$ & $\begin{array}{l}\text { Admission } \\
\text { pathology }\end{array}$ & $\begin{array}{l}\text { SAPSII } \\
\text { PEEP: } \\
\mathrm{CmH}_{2} \mathrm{O}\end{array}$ & $\begin{array}{l}\text { PS: } \\
\mathrm{CmH}_{2} \mathrm{O}\end{array}$ \\
\hline 1 & 90 & 27.8 & SE-COPD & 38 & 10 & 14 & 0.40 \\
2 & 92 & 29.1 & SE-COPD & 34 & 10 & 14 & 0.50 \\
3 & 70 & 23.7 & Pneumonia & 28 & 10 & 10 & 0.40 \\
4 & 87 & 28.2 & Sepsis & 37 & 5 & 15 & 0.35 \\
5 & 75 & 24.5 & Polytrauma & 44 & 5 & 12 & 0.30 \\
6 & 80 & 26.1 & Polytrauma & 29 & 5 & 15 & 0.35 \\
7 & 64 & 23.5 & Pneumonia & 38 & 5 & 12 & 0.40 \\
8 & 70 & 25.7 & Pneumonia & 38 & 5 & 8 & 0.50 \\
9 & 60 & 22.0 & Pneumonia & 27 & 5 & 10 & 0.40 \\
10 & 67 & 24.1 & SE-COPD & 39 & 7 & 12 & 0.35 \\
11 & 50 & 19.5 & Pneumonia & 56 & 5 & 10 & 0.40 \\
12 & 60 & 20.8 & Pneumonia & 57 & 7 & 12 & 0.40 \\
13 & 58 & 19.6 & CPE & 47 & 8 & 10 & 0.40 \\
14 & 70 & 25.1 & Sepsis & 40 & 5 & 10 & 0.40 \\
\hline
\end{tabular}

BMI body mass index, SAPSII Simplified Acute Physiology Score II, PEEP Positive end-expiratory pressure, $\mathrm{PS}$ pressure support, $\mathrm{FiO}_{2}$ inspired fraction of oxygen, $S E-C O P D$ severe exacerbation of chronic obstructive pulmonary disease, $C P E$ cardiac pulmonary edema

reduced by $\mathrm{PS}_{\mathrm{N}}$, as opposed to both $\mathrm{PS}_{\mathrm{P}}$ and NAVA $(p<0.001$ for both comparison), with no differences between $\mathrm{PS}_{\mathrm{P}}$ and NAVA $(p=0.217)$. Figure 3 shows, from top to bottom, Paw, flow and EAdi tracings of one representative patient undergoing $\mathrm{PS}_{\mathrm{P}}$ (left), NAVA (middle) and $\mathrm{PS}_{\mathrm{N}}$ (right). The arrow indicates an ineffective inspiratory effort during $\mathrm{PS}_{\mathrm{P}}$. The median group values are presented in Table 2 .

Gas exchanges were no different between trials (Table 2).

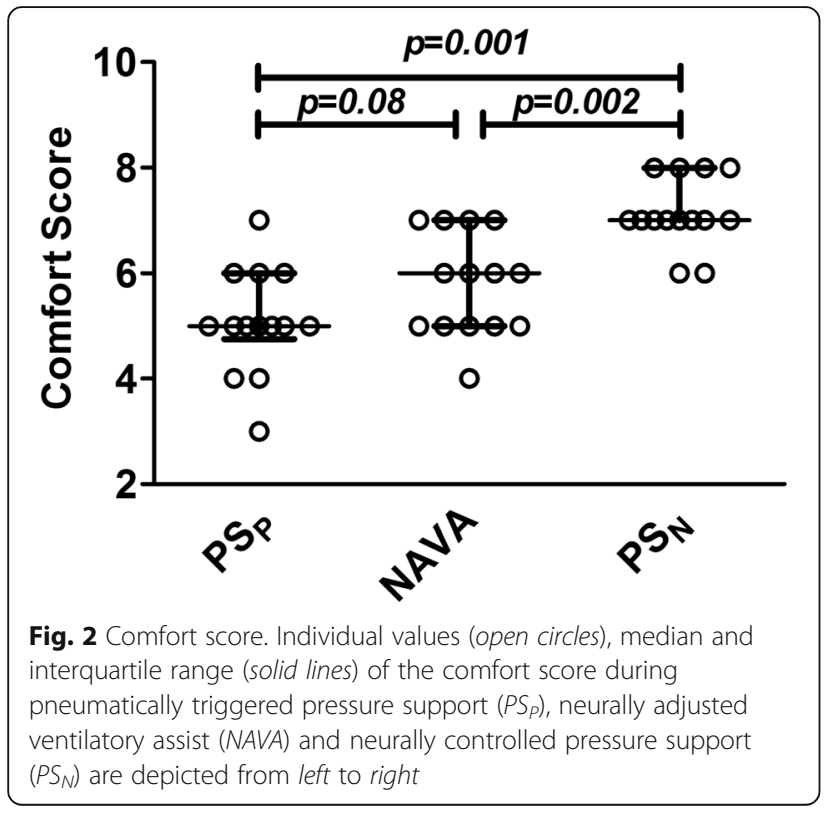

\section{Pressurization and triggering performance}

Figure 4 depicts Paw profiles of individual breaths during $\mathrm{PS}_{\mathrm{P}}$ (solid line), NAVA (dotted line) and $\mathrm{PS}_{\mathrm{N}}$ (dashed line) from another patient. The arrow indicates the beginning of the patient's own (neural) effort. $\mathrm{PS}_{\mathrm{P}}$ and $\mathrm{PS}_{\mathrm{N}}$ have similar Paw profiles, characterized by a fast rate of pressurization; however, during $\mathrm{PS}_{\mathrm{N}}$ the beginning of pressurization is notably anticipated and closer to the onset of the patient's effort. NAVA is characterized by a slower rate of pressurization. Consistent with these findings, $\mathrm{PS}_{\mathrm{N}}$ improved both $\mathrm{PTP}_{300 \text {-index }}$ and $\mathrm{PTP}_{500 \text {-index }}$, as opposed to both $\mathrm{PS}_{\mathrm{P}}$ and NAVA (Table 2), whereas $\mathrm{PTP}_{200}$ was lower during NAVA, as compared to both $\mathrm{PS}_{\mathrm{P}}$ and $\mathrm{PS}_{\mathrm{N}}(p<0.001$ for both comparisons), with no significant difference between $\mathrm{PS}_{\mathrm{P}}$ and $\mathrm{PS}_{\mathrm{N}}(p=0.761)$. Shown also in Table 2, NAVA and $\mathrm{PS}_{\mathrm{N}}$ significantly reduced Delay ${ }_{\mathrm{TR} \text {-insp }}$, PTPt and $\Delta \mathrm{P}_{\text {trigger }}$ in contrast to $\mathrm{PS}_{\mathrm{P}}$ $\left(p<0.001\right.$ for all comparisons). Delay ${ }_{\text {TR-exp }}$ was no different between modes $(p=0.395)$.

\section{Patient-ventilator synchrony}

Compared to $\mathrm{PS}_{\mathrm{B}}$ both NAVA $(p=0.005)$ and $\mathrm{PS}_{\mathrm{N}}(p=$ $0.002)$ improved Time synch $/ \mathrm{TI}_{\text {neu }}$, with no differences between the two $(p=0.08)$ (Table 2). The median values of AI\% are reported in Table 2. As expected, during both NAVA and $\mathrm{PS}_{\mathrm{N}}$, the $\mathrm{AI} \%$ was $<10 \%$ in all patients, whereas it was $\geq 10 \%$ in 7 patients $(50 \%)$ with $\mathrm{PS}_{\mathrm{P}}(p=0.023$, compared to both NAVA and $\mathrm{PS}_{\mathrm{N}}$ ).

\section{Discussion}

This physiologic study shows that in patients receiving NIV by facial mask, compared to both $\mathrm{PS}_{\mathrm{P}}$ and NAVA, $\mathrm{PS}_{\mathrm{N}}$ improves pressurization and triggering performance, resulting in better comfort, while not affecting respiratory drive, Arterial Blood Gases ABGs and respiratory rate. Both $\mathrm{PS}_{\mathrm{N}}$ and NAVA equally improve patient-ventilator synchrony, in contrast to $\mathrm{PS}_{\mathrm{P}}$.

To the best of our knowledge, this investigation is the first to evaluate $\mathrm{PS}_{\mathrm{N}}$ for delivery of NIV using a mask. In a study evaluating intubated patients with COPD and intrinsic PEEP, compared to $\mathrm{PS}_{\mathrm{B}}, \mathrm{PS}_{\mathrm{N}}$ improved patientventilator interaction and synchrony, and counterbalanced the extra load due to intrinsic PEEP without the need for externally applied PEEP [16]. In healthy volunteers, comfort was reduced when increasing the level of support [29], whereas it was improved by EAdi triggering, as opposed to pneumatic triggering, during NIV delivered by helmet [30]. In a recent study comparing $\mathrm{PS}_{\mathrm{N}}$ with $\mathrm{PS}_{\mathrm{P}}$ and NAVA during NIV delivered by helmet in an analogous patient population, $\mathrm{PS}_{\mathrm{N}}$ improved comfort, pressurization and triggering performance, and reduced EAdi, without affecting gas exchange [4].

Consistent with the results of these investigations, in the present study $\mathrm{PS}_{\mathrm{N}}$ outperforms $\mathrm{PS}_{\mathrm{P}}$ with respect to 
Table 2 Breathing pattern, respiratory drive, gas exchange, pressurization and triggering performance and patient-ventilator synchrony

\begin{tabular}{|c|c|c|c|c|}
\hline & Friedman test ( $p$ value) & $P S_{p}$ & NAVA & $P S_{N}$ \\
\hline \multicolumn{5}{|c|}{ Breathing pattern and respiratory drive } \\
\hline $\mathrm{RR}_{\text {mec }}$ (breaths/min) & 0.606 & $23.9(18.7 ; 30.6)$ & $26.7(19.5 ; 30.6)$ & $27.4(18.4 ; 31.7)$ \\
\hline $\mathrm{RR}_{\text {neu }}$ (breaths/min) & 0.931 & $25.7(18.6 ; 32.9)$ & $26.2(19.6 ; 30.7)$ & $26.4(19.3 ; 30.8)$ \\
\hline $\mathrm{TI}_{\mathrm{mec}}(\mathrm{sec})$ & 0.168 & $0.71(0.58 ; 0.87)$ & $0.83(0.61 ; 1.11)$ & $0.82(0.66 ; 1.04)$ \\
\hline $\mathrm{TI}$ neu $(\mathrm{sec})$ & 0.606 & $0.75(0.56 ; 1.10)$ & $0.74(0.59 ; 1.10)$ & $0.75(0.59 ; 0.96)$ \\
\hline TI/TTOT mec & 0.030 & $0.30(0.27 ; 0.33)$ & $0.33(0.31 ; 0.40)^{*}$ & $0.34(0.29 ; 0.41)^{\#}$ \\
\hline $\mathrm{TI} / \mathrm{TTOT}$ neu & 0.606 & $0.32(0.26 ; 0.37)$ & $0.32(0.28 ; 0.38)$ & $0.30(0.26 ; 0.34)$ \\
\hline Paw & 0.607 & $19.3(15.1 ; 21.1)$ & $18.8(15.4 ; 21.0)$ & $19.0(15.2 ; 20.5)$ \\
\hline Leaks \% & 0.395 & $21.4(8.9 ; 43.2)$ & $35.9(15.2 ; 47.6)$ & $23.2(11.5 ; 61.9)$ \\
\hline PIF (I/sec) & 0.109 & $1.12(0.85 ; 1.42)$ & $1.05(0.71 ; 1.22)$ & $1.20(0.77 ; 1.38)$ \\
\hline $\mathrm{PIF}_{\text {time }}(\mathrm{sec})$ & $<0.001$ & $0.41(0.34-0.48)$ & $0.41(0.33-0.58)$ & $0.22(0.19-0.26)^{\# \S}$ \\
\hline EAdi $_{\text {peak }}(\mu \mathrm{V})$ & 0.257 & $13.7(7.7 ; 21.2)$ & $15.3(8.4 ; 25.7)$ & $12.6(6.9 ; 19.3)$ \\
\hline \multicolumn{5}{|l|}{ Gas exchange } \\
\hline $\mathrm{pH}$ & 0.4576 & $7.43(7.40 ; 7.45)$ & $7.43(7.40 ; 7.45)$ & $7.43(7.40 ; 7.45)$ \\
\hline $\mathrm{PaCO}_{2}$ & 0.5134 & $44.1(36.2 ; 50.3)$ & $44.4(36.1 ; 51.5)$ & $43.8(38.2 ; 50.8)$ \\
\hline $\mathrm{PaO}_{2} / \mathrm{FiO}_{2}$ & 0.5103 & $213.6(197.9 ; 224.0)$ & $214.6(188.1 ; 238.0)$ & $214.4(199.0 ; 226.2)$ \\
\hline \multicolumn{5}{|c|}{ Pressurization and triggering performance } \\
\hline PTP 300 -index $(\%)$ & 0.004 & $24.7(4.3 ; 32.7)$ & $25.3(19.9 ; 34.0)$ & $42.0(32.5 ; 46.5)^{\# \S}$ \\
\hline PTP $_{500-\text {-index }}(\%)$ & 0.001 & $44.2(23.3 ; 52.1)$ & $46.4(33.4 ; 56.6)$ & $62.6(54.1 ; 67.9)^{\# \S}$ \\
\hline $\mathrm{PTP}_{200}\left(\mathrm{cmH}_{2} \mathrm{O} / \mathrm{sec}\right)$ & 0.001 & $86.7(77.5 ; 112.5)$ & $62.1(45.7 ; 81.9)^{*}$ & $85.0(69.6 ; 127.4)^{\S}$ \\
\hline PTPt $\left(\mathrm{cmH}_{2} \mathrm{O} / \mathrm{sec}\right)$ & $<0.001$ & $9.45(5.89 ; 12.31)$ & $0.89(0.23 ; 3.23)^{*}$ & $0.59(0.16 ; 2.33)^{\#}$ \\
\hline$\Delta P_{\text {trigger }}\left(\mathrm{cmH}_{2} \mathrm{O}\right)$ & $<0.001$ & $-1.16(-1.40 ;-0.87)$ & $-0.36(-0.78 ;-0.11)^{*}$ & $-0.32(-0.71 ;-0.11)^{\#}$ \\
\hline \multicolumn{5}{|c|}{ Patient ventilator synchrony } \\
\hline Delay $_{\text {TR-insp }}$ (sec) & $<0.001$ & $0.13(0.08 ; 0.27)$ & $0.07(0.03 ; 0.06)^{*}$ & $0.05(0.04 ; 0.06)^{\#}$ \\
\hline Delaytr-exp (sec) & 0.395 & $0.13(0.05 ; 0.22)$ & $0.10(0.09 ; 0.14)$ & $0.11(0.10 ; 0.12)$ \\
\hline Time $_{\text {synch }} / T I_{\text {neu }}$ & 0.010 & $0.79(0.70 ; 0.88)$ & $0.90(0.86 ; 0.94)^{*}$ & $0.94(0.89 ; 0.98)^{\#}$ \\
\hline Al\% (\%) & $<0.001$ & $6.6(0.0 ; 23.4)$ & $0.0(0.0 ; 0.0)^{*}$ & $0.0(0.0 ; 0.0)^{\#}$ \\
\hline
\end{tabular}

$P S_{P}$ pneumatically triggered and cycled-off pressure support, $N A V A$ neurally adjusted ventilatory assist, $P S_{N}$ neurally controlled pressure support, $R R_{m e c}$ ventilator respiratory rate, $R R_{\text {neu }}$ patient's respiratory rate, $T I_{\text {mec }}$ inspiratory time of the ventilator, $T I_{\text {neu }}$ inspiratory time of the patient, $T I / T O T_{\text {mec }}$ ventilator inspiratory duty cycle, TI/TOT neu patient's inspiratory duty cycle, Paw $_{\text {peak }}$ peak airway pressure, PIF peak inspiratory flow, $P I F_{\text {time }}$ time to reach the PIF, EAdi electrical activity of the diaphragm, EAdi peak peak value of EAdi, $\mathrm{PaCO}_{2}$ arterial partial pressure of carbon dioxide, $\mathrm{PaO}_{2} / \mathrm{FiO}_{2}$ ratio between arterial partial pressure and inspired fraction of oxygen, PTP pressure time product, PTP 300 -index PTP of the first 300 ms since the effort of the patient indexed to the ideal PTP, PTP 500 -index PTP of the first $500 \mathrm{~ms}$ since the effort of the patient indexed to the ideal PTP, PTP 200 PTP of the first 200 ms since the beginning of pressurization, PTPt PTP of the trigger, $\Delta P_{\text {trigger }}$ drop of pressure during triggering phase, Delay ${ }_{T R \text {-insp }}$ inspiratory trigger delay, Dealy TR-exp $_{\text {expiratory trigger delay, Time }}$ synch $/ T I_{\text {neu }}$ synchronous

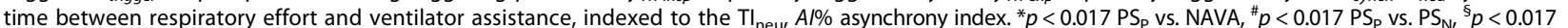
NAVA vs. PS

PTP $_{300-i n d e x}$ and PTP ${ }_{500-i n d e x}$ PTPt $[4,16,30]$, DelayTR-insp, Time $_{\text {synch }} / \mathrm{TI}_{\text {neu }}$ and AI $[4,16,30]$, and comfort $[4,30]$. In accordance with Cammarota et al. [4], who compared the same three modes delivering NIV by helmet, $\mathrm{PS}_{\mathrm{N}}$ improved pressurization $\mathrm{PTP}_{300 \text {-index }}$ and $\mathrm{PTP}_{500 \text {-index }}$, and comfort with respect to both $\mathrm{PS}_{\mathrm{P}}$ and NAVA, while in contrast to that study, $\mathrm{PS}_{\mathrm{N}}$ neither increased $\mathrm{PTP}_{200}$, compared to $\mathrm{PS}_{\mathrm{P}}$, nor reduced EAdi, compared to both $\mathrm{PS}_{\mathrm{P}}$ and NAVA. These discrepancies are likely due to the different physical properties of mask and helmet, the latter being characterized by more problematic triggering and pressurization performance [31]. Nonetheless, we found improvements in triggering and pressurization performance to ameliorate comfort, which is a major determinant of NIV outcome. Indeed, NIV can be complicated by discomfort, which is associated with increased rate of failure and worsened patient outcome [32].

PIF was not different between modes, while PIF $_{\text {time }}$ was shortened by $\mathrm{PS}_{\mathrm{N}}$, as opposed to both $\mathrm{PS}_{\mathrm{P}}$ and NAVA. In intubated patients with acute on chronic respiratory failure undergoing $\mathrm{PS}_{\mathrm{P}}$, Bonmarchand et al. evaluated the effects of varying Paw rates of pressurization; they found that the fastest rate generated the highest PIF and was associated with greater 



Fig. 4 Pressure airway profiles. Airway pressure (Paw) profile of single breaths during pneumatically triggered pressure support (solid line), neurally adjusted ventilatory assist (dotted line) and neurally controlled pressure support (dashed line) from another patient. The arrow indicates the beginning of the patient's effort. See main text for additional explanation reduction in the work of breathing [33]. Similar results were obtained during invasive $\mathrm{PS}_{\mathrm{N}}$ in restrictive patients [34] and in patients recovering from hypoxemic ARF [35].

To explain the differences between these studies and our investigation, it is important to note the different computational approach to the pressurization indexes [27]. $\mathrm{PTP}_{200}$ reflects the sole rate of pressurization rate, i.e., the slope of Paw after triggering, which affects the PIF. Both PTP 300 -index and PTP 500 -index instead consider not only the pressurization rate but also the triggering performance, which influences PIF $_{\text {time, }}$, without affecting PIF. We found $\mathrm{PTP}_{200}$ no different between $\mathrm{PS}_{\mathrm{N}}$ and $\mathrm{PS}_{\mathrm{P}}$, while triggering performance was significantly improved by $\mathrm{PS}_{\mathrm{N}}$, as indicated by the lower values of PTPt and DelayTR-insp. Notably, while patient comfort is improved when flow delivery by the ventilator meets the patient's demand [36], excessively high PIF may worsen the patient's comfort during both invasive ventilation [37] and NIV [36].

Our study has two limitations. First, the patient sample is small, a limitation that we share with the majority of earlier physiological investigations [4, 9, 11-13, 15, 24, 37, 38]. Second, consistent with the results of previous research [4, 22-24], we applied the 11-point NRS to assess comfort, although this scale has been formally validated for pain $[39,40]$ and dyspnoea [41] only.

\section{Conclusions}

Compared to both $\mathrm{PS}_{\mathrm{P}}$ and NAVA, in patients receiving NIV by facial mask, $\mathrm{PS}_{\mathrm{N}}$ improves triggering performance and patient-ventilator synchrony, thereby ameliorating the patient's comfort. It remains to be determined whether these physiologic benefits may also occur in other categories of patients and translate into improved clinical outcomes.

\section{Abbreviations}

Al\%: Asynchrony index; ARF: Acute respiratory failure; COPD: Chronic obstructive pulmonary disease; Delay TR-exp: Expiratory trigger delay; Delay TR-insp: Inspiratory trigger delay; EAdi: Diaphragm electrical activity; EAdi $i_{\text {peak: }}$ : Peak of electrical activity of the diaphragm; $\mathrm{FiO}_{2}$ : Inspiratory oxygen fraction; GCS: Glasgow Coma Scale; ICUs: Intensive Care Units; NAVA: Neurally adjusted ventilatory assist; NIV: Noninvasive ventilation; NRS: Numeric rating scale; $\mathrm{PaCO}_{2}$ : Arterial partial pressure of carbon dioxide; Paw: Airway pressure; Paw peak: Peak of airway pressure; PEEP: Positive end-expiratory pressure; PIF: Peak inspiratory flow; $\mathrm{PIF}_{\text {time: }}$ Time to reach the peak inspiratory flow from the onset of patient's effort; $P S_{\mathrm{N}}$ : Neurally controlled pressure support; PSp: Pneumatically triggered and cycled-off pressure support; PTP: Pressuretime product; PTP $_{200}$ : Pressure-time product of the first $200 \mathrm{~ms}$ from the

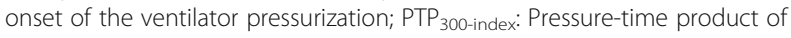
the first $300 \mathrm{~ms}$ from the onset of the neural effort, indexed to the ideal area; PTP $_{500-\text { index: }}$ Pressure-time product of the first $500 \mathrm{~ms}$ from the onset of the neural effort, indexed to the ideal area; PTP: Pressure-time product of the triggering phase; $R R_{\text {mec }}$ : Rate of ventilator cycling; $R_{\text {neu }}$ : Patient's own (neural) respiratory rate; $\mathrm{SpO}_{2}$ : Peripheral oxygen saturation;

TI/TTOT mec: Mechanical inspiratory duty cycle; TI/TTOT neu: Patient's own (neural) inspiratory duty cycle; $\mathrm{TI}_{\text {mec }}$ : Mechanical inspiratory time;

Time $_{\text {synch }} / \mathrm{TI}$ neu: Time during which respiratory effort and ventilator assistance are synchronous, indexed to the patient's own (neural) inspiratory time; 
$T I_{\text {neu: }}$ Patient's own (neural) inspiratory time; $\mathrm{TTOT}_{\text {mec: }}$ Total mechanical respiratory time; TTOT neu: Total patient's own (neural) respiratory time; $\Delta P_{\text {trigger: }}$ Pressure drop of the triggering phase

\section{Acknowledgements}

None.

\section{Funding}

Maquet Critical Care (Solna, Sweden) provided the NAVA module and catheters used for the study. A portion of the results from this study was presented in abstract form at the International Symposium on Intensive Care and Emergency Medicine in Brussels (2014).

\section{Availability of data and materials}

The full protocol and raw data are available at longhini.federico@gmail.com.

\section{Authors' contributions}

FL was responsible for conception and design of the study, acquisition, analysis and interpretation of the data and for drafting and revising the article for final approval of the version to be published. CP was responsible for the conception and design of the study, acquisition, analysis and interpretation of data and for drafting and revising the article for final approval of the version to be published. JX and GC were responsible for the acquisition of data and for revising the article for final approval of the version to be published. AB and EG were responsible for analysis and interpretation of the data and for drafting and revising the article for final approval of the version to be published. YY participated in the design of the stud, acquisition and analysis of the data and in revising the article for final approval of the version to be published. PN and HQ were responsible for the conception and design of the study, analysis and interpretation of data and for drafting and revising the article for important intellectual content and final approval of the version to be published. All authors have read and approved the final manuscript.

\section{Ethics approval and consent to participate}

The study was approved by the local Ethics Committees "A.O.U Maggiore della Carità" in Novara, Italy (protocol n ${ }^{\circ}$ 64/12) and the Research Ethics Board of Zhongda Hospital, Southeast University, Nanjing, China (2013ZDSYLL097.0). Written informed consent was obtained from each participant before inclusion in the study, according to the local regulations and principles outlined in the Helsinki declaration. At the time the study was conducted, trial registration was not mandatory for this type of investigation.

\section{Competing interests}

PN contributed to the development of the helmet, Next (Castar Next, Intersurgical, Mirandola, Italy), whose license for the patent belongs to Intersurgical S.P.A., and received royalties for that invention. PN's research laboratory has received equipment and/or grants from Maquet Critical Care (Solna, Sweden), Intersurgical S.p.A. (Mirandola, Italy), Draeger Medical GmbH (Corsico, Italy), Biotest (Trezzano sul Naviglio, Italy) and Hillrom (Bussigny, Switzerland). PN received honoraria/speaking fees from Maquet Critical Care (Solna, Sweden), Covidien AG (Segrate, Italy), Draeger Medical GmbH (Corsico, Italy), Breas (Mölnlycke, Sweden), Hillrom (Chicago, IL, USA), Resmed (Vimercate MB, Italy) and Linde AG (Munich, Germany). All other authors declare that they have no competing interests.

\section{Consent for publication}

All patients gave consent for data publication according to national regulations.

\section{Publisher's Note}

Springer Nature remains neutral with regard to jurisdictional claims in published maps and institutional affiliations.

\section{Author details}

'Anesthesia and Intensive Care, Sant'Andrea Hospital, ASL VC, Vercelli, Italy. ${ }^{2}$ Department of Critical Care Medicine, Nanjing Zhong-Da Hospital, Southeast University School of Medicine, 87 Dingjiagiao Road, Nanjing 210009, China. ${ }^{3}$ Anesthesia and Intensive Care, "Maggiore della Carità" Hospital, Novara, Italy. ${ }^{4}$ Intensive Care Unit, University Hospital Mater Domini, Department of Medical and Surgical Sciences, Magna Graecia University, Catanzaro, Italy.
Received: 3 February 2017 Accepted: 19 June 2017

Published online: 07 July 2017

\section{References}

1. Esteban A, Frutos-Vivar F, Muriel A, Ferguson ND, Penuelas O, Abraira V, Raymondos K, Rios F, Nin N, Apezteguia C, et al. Evolution of mortality over time in patients receiving mechanical ventilation. Am J Respir Crit Care Med. 2013;188(2):220-30.

2. Nava S, Navalesi P, Carlucci A. Non-invasive ventilation. Minerva Anestesiol. 2009;75(1-2):31-6.

3. Crimi C, Noto A, Princi P, Nava S. Survey of non-invasive ventilation practices: a snapshot of Italian practice. Minerva Anestesiol. 2011;77(10):971-8.

4. Cammarota G, Longhini F, Perucca R, Ronco C, Colombo D, Messina A, Vaschetto R, Navalesi P. New setting of neurally adjusted ventilatory assist during noninvasive ventilation through a helmet. Anesthesiology. 2016;125(6):1181-9

5. Antonelli M, Conti G, Pelosi P, Gregoretti C, Pennisi MA, Costa R, Severgnini P, Chiaranda M, Proietti R. New treatment of acute hypoxemic respiratory failure: noninvasive pressure support ventilation delivered by helmet-a pilot controlled trial. Crit Care Med. 2002;30(3):602-8.

6. Calderini E, Confalonieri M, Puccio PG, Francavilla N, Stella L, Gregoretti C. Patient-ventilator asynchrony during noninvasive ventilation: the role of expiratory trigger. Intensive Care Med. 1999;25(7):662-7.

7. Vignaux L, Vargas F, Roeseler J, Tassaux D, Thille AW, Kossowsky MP, Brochard $L$, Jolliet P. Patient-ventilator asynchrony during non-invasive ventilation for acute respiratory failure: a multicenter study. Intensive Care Med. 2009;35(5):840-6.

8. Navalesi P. Longhini F. Neurally adjusted ventilatory assist. Curr Opin Crit Care. 2015;21(1):58-64.

9. Colombo D, Cammarota G, Bergamaschi V, De Lucia M, Corte FD, Navalesi P. Physiologic response to varying levels of pressure support and neurally adjusted ventilatory assist in patients with acute respiratory failure. Intensive Care Med. 2008;34(11):2010-8.

10. Vaschetto R, Cammarota G, Colombo D, Longhini F, Grossi F, Giovanniello A Della Corte F, Navalesi P. Effects of propofol on patient-ventilator synchrony and interaction during pressure support ventilation and neurally adjusted ventilatory assist*. Crit Care Med. 2014:42(1):74-82.

11. Schmidt M, Dres M, Raux M, Deslandes-Boutmy E, Kindler F, Mayaux J, Similowski T, Demoule A. Neurally adjusted ventilatory assist improves patient-ventilator interaction during postextubation prophylactic noninvasive ventilation. Crit Care Med. 2012:40(6):1738-44.

12. Bertrand PM, Futier E, Coisel Y, Matecki S, Jaber S, Constantin JM. Neurally adjusted ventilatory assist vs pressure support ventilation for noninvasive ventilation during acute respiratory failure: a crossover physiologic study. Chest. 2013;143(1):30-6.

13. Piquilloud L, Tassaux D, Bialais E, Lambermont B, Sottiaux T, Roeseler J, Laterre PF, Jolliet P, Revelly JP. Neurally adjusted ventilatory assist (NAVA) improves patient-ventilator interaction during non-invasive ventilation delivered by face mask. Intensive Care Med. 2012;38(10):1624-31.

14. Doorduin J, Sinderby CA, Beck J, van der Hoeven JG, Heunks L. Automated patient-ventilator interaction analysis during neurally adjusted non-invasive ventilation and pressure support ventilation in chronic obstructive pulmonary disease. Crit Care. 2014;18(5):550.

15. Cammarota G, Olivieri C, Costa R, Vaschetto R, Colombo D, Turucz E, Longhini F, Della Corte F, Conti G, Navalesi P. Noninvasive ventilation through a helmet in postextubation hypoxemic patients: physiologic comparison between neurally adjusted ventilatory assist and pressure support ventilation. Intensive Care Med. 2011;37(12):1943-50.

16. Liu L, Xia F, Yang Y, Longhini F, Navalesi P, Beck J, Sinderby C, Qiu H. Neural versus pneumatic control of pressure support in patients with chronic obstructive pulmonary diseases at different levels of positive end expiratory pressure: a physiological study. Crit Care. 2015;19:244.

17. Altman DG, Schulz KF, Moher D, Egger M, Davidoff F, Elbourne D, Gotzsche PC, Lang T. The revised CONSORT statement for reporting randomized trials: explanation and elaboration. Ann Intern Med. 2001;134(8):663-94

18. Navalesi P, Frigerio P, Moretti MP, Sommariva M, Vesconi S, Baiardi P, Levati A. Rate of reintubation in mechanically ventilated neurosurgical and neurologic patients: evaluation of a systematic approach to weaning and extubation. Crit Care Med. 2008;36(11):2986-92. 
19. Nava S, Gregoretti C, Fanfulla F, Squadrone E, Grassi M, Carlucci A, Beltrame F Navalesi P. Noninvasive ventilation to prevent respiratory failure after extubation in high-risk patients. Crit Care Med. 2005;33(11):2465-70.

20. Ferrer M, Sellares J, Valencia M, Carrillo A, Gonzalez G, Badia JR, Nicolas JM, Torres A. Non-invasive ventilation after extubation in hypercapnic patients with chronic respiratory disorders: randomised controlled trial. Lancet. 2009;374(9695):1082-8.

21. SERVO-i VENTILATOR SYSTEM V6.0, User's Manual, Rev 14 English edn: Maquet Critical Care AB; 2011.

22. Chooi CS, White AM, Tan SG, Dowling K, Cyna AM. Pain vs comfort scores after Caesarean section: a randomized trial. Br J Anaesth. 2013;110(5):780-7.

23. Maggiore SM, Idone FA, Vaschetto R, Festa R, Cataldo A, Antonicelli F, Montini L, De Gaetano A, Navalesi P, Antonelli M. Nasal high-flow versus Venturi mask oxygen therapy after extubation. Effects on oxygenation, comfort, and clinical outcome. Am J Respir Crit Care Med. 2014;190(3):282-8.

24. Olivieri C, Longhini F, Cena T, Cammarota G, Vaschetto R, Messina A, Berni P, Magnani C, Della Corte F, Navalesi P. New versus conventional helmet for delivering noninvasive ventilation: a physiologic, crossover randomized study in critically ill patients. Anesthesiology. 2016;124(1):101-8.

25. Navalesi P, Hernandez P, Wongsa A, Laporta D, Goldberg P, Gottfried SB. Proportional assist ventilation in acute respiratory failure: effects on breathing pattern and inspiratory effort. Am J Respir Crit Care Med. 1996;154(5):1330-8.

26. Bellani G, Mauri T, Coppadoro A, Grasselli G, Patroniti N, Spadaro S, Sala V, Foti G, Pesenti A. Estimation of patient's inspiratory effort from the electrical activity of the diaphragm. Crit Care Med. 2013;41(6):1483-91.

27. Olivieri C, Costa R, Conti G, Navalesi P. Bench studies evaluating devices for non-invasive ventilation: critical analysis and future perspectives. Intensive Care Med. 2012;38(1):160-7.

28. Olivieri C, Costa R, Spinazzola G, Ferrone G, Longhini F, Cammarota G, Conti G, Navalesi P. Bench comparative evaluation of a new generation and standard helmet for delivering non-invasive ventilation. Intensive Care Med. 2013:39(4):734-8.

29. Costa R, Navalesi P, Antonelli M, Cavaliere F, Craba A, Proietti R, Conti G. Physiologic evaluation of different levels of assistance during noninvasive ventilation delivered through a helmet. Chest. 2005;128(4):2984-90.

30. Moerer O, Beck J, Brander L, Costa R, Quintel M, Slutsky AS, Brunet F, Sinderby C. Subject-ventilator synchrony during neural versus pneumatically triggered non-invasive helmet ventilation. Intensive Care Med. 2008;34(9):1615-23.

31. Costa R, Navalesi P, Spinazzola G, Ferrone G, Pellegrini A, Cavaliere F, Proietti R, Antonelli M, Conti G. Influence of ventilator settings on patient-ventilator synchrony during pressure support ventilation with different interfaces. Intensive Care Med. 2010;36(8):1363-70.

32. Lemyze M, Mallat J, Nigeon O, Barrailler S, Pepy F, Gasan G, Vangrunderbeeck N, Grosset P, Tronchon L, Thevenin D. Rescue therapy by switching to total face mask after failure of face mask-delivered noninvasive ventilation in do-not-intubate patients in acute respiratory failure. Crit Care Med. 2013;41(2):481-8

33. Bonmarchand G, Chevron V, Chopin C, Jusserand D, Girault C, Moritz F, Leroy J, Pasquis $P$. Increased initial flow rate reduces inspiratory work of breathing during pressure support ventilation in patients with exacerbation of chronic obstructive pulmonary disease. Intensive Care Med. 1996;22(11):1147-54.

34. Bonmarchand G, Chevron V, Menard JF, Girault C, Moritz-Berthelot F, Pasquis $P$, Leroy J. Effects of pressure ramp slope values on the work of breathing during pressure support ventilation in restrictive patients. Crit Care Med. 1999;27(4):715-22.

35. Chiumello D, Pelosi P, Taccone P, Slutsky A, Gattinoni L. Effect of different inspiratory rise time and cycling off criteria during pressure support ventilation in patients recovering from acute lung injury. Crit Care Med. 2003;31(11):2604-10.

36. Prinianakis $G$, Delmastro $M$, Carlucci $A$, Ceriana $P$, Nava S. Effect of varying the pressurisation rate during noninvasive pressure support ventilation. Eur Respir J. 2004;23(2):314-20

37. Chiumello D, Pelosi P, Croci M, Bigatello LM, Gattinoni L. The effects of pressurization rate on breathing pattern, work of breathing, gas exchange and patient comfort in pressure support ventilation. Eur Respir J. $2001 ; 18(1): 107-14$.

38. Vargas F, Thille A, Lyazidi A, Campo FR, Brochard L. Helmet with specific settings versus facemask for noninvasive ventilation. Crit Care Med. 2009;37(6):1921-8.
39. Gerbershagen HJ, Rothaug J, Kalkman CJ, Meissner W. Determination of moderate-to-severe postoperative pain on the numeric rating scale: a cut-off point analysis applying four different methods. Br J Anaesth. 2011;107(4):619-26.

40. Gagliese L, Weizblit N, Ellis W, Chan W. The measurement of postoperative pain: a comparison of intensity scales in younger and older surgical patients. Pain. 2005;117(3):412-20.

41. Gift AG, Narsavage G. Validity of the numeric rating scale as a measure of dyspnea. Am J Crit Care. 1998;7(3):200-4.

\section{Submit your next manuscript to BioMed Central and we will help you at every step:}

- We accept pre-submission inquiries

- Our selector tool helps you to find the most relevant journal

- We provide round the clock customer support

- Convenient online submission

- Thorough peer review

- Inclusion in PubMed and all major indexing services

- Maximum visibility for your research

Submit your manuscript at www.biomedcentral.com/submit
) Biomed Central 